Lambert J, Frackowiak RSJ, Lechevalier B, Eustache F. The structural components of music perception. A functional anatomical study. Brain Feb 1997;120:229-243). (Respond: Professor Richard SJ Frackowiak, Wellcome Department of Cognitive Neurology, Institute of Neurology, London WC1N 3BG, UK).

COMMENT: The perception of music is a complex neurocognitive process involving various neural networks, with some anatomical specificity for the different basic auditory components of music (rhythm, pitch, timbre, and melody). Furthermore, visual cognitive imagery appears to be involved in pitch appreciation. Despite the recent interest in music lessons as an aid to education and academic achievement in school children, studies of the neural anatomy of music perception are fragmentary and involve mainly braindamaged subjects. The authors cite only one previous PET study in which different components of music perception were tested for brain activation (Mazziotta et al, 1982). In their sophisticated scanning procedure, Platel, Frackowiak and coworkers have demonstrated the functional independence of sub-components of musical expression. The left hemisphere is dominant for rhythm, tune recognition, and pitch perception, while the right hemisphere is involved in timbre or quality of tone perception. Within the left hemisphere, the inferior frontal and superior temporal gyri represent melody recognition and familiarity, Broca's area and the insula process rhythm and sequencing of sounds, and the cuneus/precuneus areas, reflecting visual interpretations, are involved in differentiation of pitch. As my violin teacher, Dr Marvin Ziporyn, correctly comments when I err on pitch of a chromatic scale, "It's all in the head, not in the fingers!"

In an interesting note concerning music and art by Phillip Huscher and linking the auditory with visual interpretation (Comment on Henri Dutilleux's composition, Timbres, espace, mouvement, based on van Gogh's painting, The Starry Night. In: Notebook, Program of the Chicago Symphony Orchestra, April 3, 4 \& 5, 1997;53C-E), few composers have transposed artistic canvases into musical compositions, whereas many artists have been inspired by music, notably Rubens and Raphael, in their depiction of Saint Cecilia, the patron saint of music. (P.S. I am sure that many of our readers could supply lists of musical compositions or songs based on museum works of art. PNB Publishers will offer a complimentary copy of the Editor's new book, Progress in Pediatric Neurology III, to the PNB subscriber submitting the longest list of composers with verifiable compositions based on museum works of art.)

\title{
HEMISPHERIC ANOMALIES IN ADHD: MRI ANALYSES
}

Volumetric MRI brain analyses were compared in 15 male ADHD subjects without comorbidity (mean age, 12.4 years) and 15 normal controls at the University of California, Irvine, CA. ADHD children had smaller volumes of the following structures: left caudate, right anterior-superior (frontal) hemispheric region, bilateral anterior-inferior (peri-basal ganglia) hemispheric region, and bilateral retrocallosal (posterior parieto-occipital) region white matter. The caudate size was correlated with response to stimulant medication; responders had the smallest and symmetric caudate volumes, whereas nonresponders had reversed caudate asymmetry and the smallest retrocallosal white matter volume. (Filipek PA, Semrud-Clikeman M, Steingard RJ, Renshaw PF, Kennedy DN, Biederman J. Volumetric MRI analysis comparing subjects having attention-deficit hyperactivity disorder with normal controls. Neurology March 1997;48:589-601). (Reprints: Dr Pauline A Filipek, Departments of Pediatrics and Neurology, 20T 4482, Bldg 27, University of 
California, Irvine, Medical Center, 101 City Drive South, Orange, CA 92868).

COMMENT. Localized hemispheric structural anomalies may occur in children with ADHD, consistent with abnormal frontal-striatal function, and possibly correlated with response to stimulant medication. A neurodevelopmental process is suggested because the hemispheric volumes are similar to controls, and the changes are not associated with ventricular enlargement or the result of atrophy.

Temporal lobe arachnoid cyst - ADHD syndrome. A cerebral developmental anomaly and syndrome is reported in three children with ADHD found on MRI to have left sided temporal lobe arachnoid cysts (Millichap JG. Temporal lobe arachnoid cyst - attention deficit disorder syndrome: Role of the electroencephalogram in diagnosis. Neurology May 1997;48: in press). The diagnosis by MRI was determined following EEGs obtained because of headaches, language delay, or episodes suggestive of partial seizures. EEGs showed focal epileptiform or slow wave abnormalities involving the left temporal region and correlating with the location of the structural temporal fossa lesions. A causal association was considered plausible because of coincidental learning and language disabilities explained by temporal lobe and sylvian region pathology.

\section{METHYLPHENIDATE EFFECTS ON ATTENTION AND LEARNING}

The effects of methylphenidate (MPH), in 2 doses $(0.3$ and $0.8 \mathrm{mg} / \mathrm{kg})$, on an attentional continuous performance task (CPT) and on a nonverbal learning task presented in two levels of difficulty, were evaluated in 23 children, aged 7 to 11 years, with attention deficit hyperactivity disorder treated at the Scottish Rite Children's Medical Center, Atlanta, GA. Attention task performance by the group was improved with low-dose MPH compared to placebo; CPT commission errors were reduced, while omission errors were not affected. On nonverbal learning and memory tasks, the easy level of task performance was improved equally with either dose of MPH, whereas the hard task was performed better with the high dose. (O'Toole K, Abramowitz A, Morris R, Dulcan M. Effects of methylphenidate on attention and nonverbal learning in children with attention-deficit hyperactivity disorder. I Am Acad Child Adolesc Psychiatry April 1997;36:531-538). (Reprints: Dr O'Toole, Department of Neuropsychology, Scottish Rite Children's Medical Center, 1001 Johnson Ferry Road, Atlanta, GA 30342).

COMMENT. Low dose methylphenidate may control impulsivity in ADHD children, whereas high doses may be required to improve retention and recall of complex nonverbal information. Cognitive function as well as behavior may be sensitive to stimulant medication, but doses must be individualized and titrated for each patient. Results of group responses may not be applied to all individuals.

Body mass is not predictive of clinical response to MPH, according to a study of 76 children with ADHD receiving doses of 5 to $20 \mathrm{mg}$ at the University of Hawaii, Honolulu, HI. (Rapport MD, Denney C. Titrating methylphenidate in children with attention-deficit/hyperactivity disorder: Is body mass predictive of clinical response? I Am Acad Child Adolesc Psychiatry, April 1997;36:523-530). Dose-response does not differ in children of varying body mass, and the dose of MPH should not be calculated on the basis of body weight. 